\title{
An exploratory study identifying where local government public health decision makers source their evidence for policy
}

\author{
Melissa Stoneham and James Dodds
}

Issue addressed: The Western Australian (WA) Public Health Bill will replace the antiquated Health Act 1911. One of the proposed clauses of the Bill requires all WA local governments to develop a Public Health Plan. The Bill states that Public Health Plans should be based on evidence from all levels, including national and statewide priorities, community needs, local statistical evidence, and stakeholder data.

Methods: This exploratory study, which targeted 533 WA local government officers, aimed to identify the sources of evidence used to generate the list of public health risks to be included in local government Public Health Plans.

Results: The top four sources identified for informing local policy were: observation of the consequences of the risks in the local community (24.5\%), statewide evidence (17.6\%), local evidence (17.6\%) and coverage in local media (16.2\%).

Conclusions: This study confirms that both hard and soft data are used to inform policy decisions at the local level. Therefore, the challenge that this study has highlighted is in the definition or constitution of evidence.

So what?: Evidence is critical to the process of sound policy development. This study highlights issues associated with what actually constitutes evidence in the policy development process at the local government level. With the exception of those who work in an extremely narrow field, it is difficult for local government officers, whose role includes policymaking, to read the vast amount of information that has been published in their area of expertise. For those who are committed to the notion of evidence-based policymaking, as advocated within the WA Public Health Bill, this presents a considerable challenge. 


\section{An exploratory study identifying where local government public health decision makers source their evidence for policy}

\section{Introduction}

The Western Australian Public Health Bill will replace the existing and antiquated Health Act 1911. One of the proposed clauses of the Bill is that all Western Australian local governments will be required to develop a Public Health Plan. A Public Health Plan though not defined in the Bill is well known in the industry and is a comprehensive set of proposed activities that inform the way in which public health is managed within a local government. ${ }^{1}$

The Western Australian Public Health Bill acknowledges that local government needs risk based and flexible mechanisms to undertake its role and to respond to community needs. It recognises that local government is the tier of government closest to the community and is a key advocate and protector of public health in the community. A long-standing criticism of public health legislation is that it tends to be reactive ${ }^{2}$ : a problem is identified and a remedy is then defined to rectify the problem. This approach is rightly criticised as allowing little capacity for innovation or planning for a healthy environment where the risk of future hazards are reduced. The draft Bill identifies a need to change the current approach and create a regulatory system that is flexible and proactive and where health planning is a key consideration for corporate strategy and planning.

\section{Public Health Planning Requirements}

The Public Health Bill, in its current form, states that a local public health plan is to identify the public health needs of the local government district, include an examination of data relating to health status and health determinants in the local government district and include a strategic framework for the identification, evaluation and management of public health risks in the local government district. ${ }^{2}$ In other words, the public health plans should be based on evidence from all levels including national and statewide priorities, community needs, local statistical evidence and stakeholder data. This exploratory study aimed to identify the sources of evidence used to generate the list of public health risks to be included in local government business and Public Health Plans.

\section{Methods}

During 2012 and 2013, local government officers in Western Australia were recruited via a direct email approach and invited to participate in an online survey, requesting they identify the public health risks that affected their local community. The Officers were asked to nominate the source/s of evidence used to support the identification of the local public health risks. 
A total of five Western Australian local governments were selected representing three metropolitan Councils and two regional Councils. These Councils were selected as they had commenced the process of developing a public health plan. In an effort to reduce bias, all professional staff members from these local governments were invited to participate in the survey. A total of 533 local government Officers completed the survey. As all Western Australian local governments differ in their organisational structure, professional categories of respondents are indicated in Table one, rather than local government departmental responders.

Insert Table One

\section{Results}

Table Two shows the most important primary sources of evidence for local government Officers when identifying public health risks relevant to their local community. The top four sources were observing the consequences of the risks in the local community (24.5\%), statewide evidence (17.6\%), local evidence (17.6\%) and coverage in local media (16.2\%).

Insert Table Two

Statewide evidence was defined as policies or plans that set strategic goals for the West Australian community. An example is the WA Health Promotion Strategic Framework 2012$2016^{3}$ which sets out WA Health's strategic directions and priorities for the prevention of chronic disease and injury over the next five years. Another is the Environmental Health Directorate Yearbook, which outlines achievements and strategic directions. ${ }^{4}$

Local evidence varied considerably between Councils however included networking with key community groups and support services whose client base had identified risks, Public Health Unit data collations and endorsed local government reports and plans.

\section{Discussion}

Using evidence to inform policy is not new. Evidence based policy making is an approach that "helps people make well informed decisions about policy, programs and projects by putting the best available evidence from research at the heart of policy development and implementation" ${ }^{5}$ (Davies 2004: 3). Shaxson identified that evidence is needed to ensure decision makers understand the policy environment and how it is changing, to appraise the likely effects of a policy and to enable choices between policy options to be made. ${ }^{6}$

Evidence-based public health calls for a solid knowledge base on disease frequency and distribution, on the determinants and consequences of disease, and on the safety, efficacy, and effectiveness of interventions and their costs. ${ }^{7}$ 
The challenge that this study has highlighted is in the definition or constitution of evidence. In the public health planning process, local government decision-makers must address complex questions about the nature and significance of the public health problem to be addressed, the nature of proposed interventions, their differential impact, costeffectiveness, acceptability and evaluation. This exploratory study found that the four most common sources of evidence used to identify local public health risks for inclusion in a Public Health Plan, were observing the consequences in the community, statewide evidence, local evidence and media reporting. There is no doubt that local and statewide evidence contained in published reports and including reflections from stakeholders are useful when contributing to the development of policy, however a review on the trustworthiness and reliability of media and personal observations as a source of evidence reveal these are less accepted and considered to be 'soft' sources.

Hard and soft data has been categorised evidence through a social sciences lens, implying objective verses subjective forms. ${ }^{8}$ Hard evidence was defined as primary quantitative data collected by researchers, secondary quantitative social and epidemiological data collected by government agencies, clinical trials and interviews or questionnaire-based social surveys. Soft evidence was classified as qualitative data such as ethnographic accounts. Contemporary public health practitioners accept and advocate for mixed methods, which include a balance of qualitative and quantitative data, practice-based wisdom, selfreflections by practitioners and community aspirations.

Of particular concern from this exploratory study was that the fourth most common source of evidence on which public health decisions and priorities were based for the public health planning processes in Western Australia, was reliance on mass media. Mass media strategies have been used in public health to educate and advocate for opinion and behavioural changes at individual, social and community levels. ${ }^{9.19 .11 .12}$ This study indicates that in over 16 per cent of cases, local government Officers make real-world health-risk policy decisions based on information reported in the media. Although newspapers reflect community attitudes, actions and in some cases opinions, relying on this data is in itself, a risky behaviour. A systematic and unbiased sample of every health related story appearing in the top 10 bestselling UK newspapers every day for one week was collated, coded and checked to identify the evidence behind every claim. ${ }^{13}$ From the 111 health claims reviewed, the vast majority were only supported by evidence categorised as "insufficient" (62\% under the World Cancer Research Fund system). After that, 10 per cent were "possible", 12 per cent were "probable", and only 15 per cent was "convincing". The remaining $1 \%$ was unclassifiable.

In public health, the generally accepted solution to developing evidenced based policy is to use an evidence hierarchy, where evidence is ranked according to a set of methodological criteria. Yet, a clear elucidation of what can be considered good evidence for policy use is 
rarely articulated. ${ }^{14}$ Given the time and resource constraints within the local government sector, it is difficult to encourage rigorous hierarchical systems at the local level and local government Officers tend to use what is available, accessible and locally applicable.it is clear from this small study, that for local government decision makers to make effective policy, they require access to a synthesis of high-quality evidence that includes qualitative and quantitative data originating from both hard and soft data sources including statewide and local evidence, community aspirations and concerns and perceived needs from Elected Members and key stakeholders.

\section{Conclusion}

With the exception of those who work in an extremely narrow field, it is difficult for local government Officers, whose role includes policy making, to read the vast amount of information that has been published in their area of expertise. For those who are committed to the notion of evidence-based policymaking as advocated within the Western Australian Public Health Bill, this presents a considerable challenge. This study has highlighted the plethora of sources of evidence used to identify public health risks, by a select group of local government Officers in Western Australia. The results indicate that both hard and soft data sources are used when identifying public health priorities and risks. Yet, a need for local governments to source and access high quality evidence is apparent as the use of media reporting was the fourth most common source of evidence on which to identify local public health risks. The development of toolkits specific to the local government sector on bridging the gap between research findings and policy development, and providing ideas on how to access these data is warranted.

Ethics

Ethics approval has been granted through Curtin University - Research with a low risk. 
References

1. Stoneham M, Robinson M \& Daube M. Public Health Planning - A Guide to developing a local public health plan. Perth: Public Health Advocacy Institute of WA, Curtin University, Western Australia, 2010.

2. WA Health Department. Public Health Bill, 2008. Available at http://www.public.health.wa.gov.au/cproot/2960/2/Draft_Public_Health_Bill.pdf

3. Department of Health, Western Australia. WA Health Promotion Strategic Framework 2012- 2016. Perth: Chronic Disease Prevention Directorate, Department of Health, Western Australia, 2012.

4. Department of Health, Western Australia. Environmental Health Directorate Yearbook 2012. Perth: Environmental Health Directorate, Department of Health, Western Australia, 2013.

5. Davies $P$. Is evidence based government possible? Jerry Lee Lecture presented at the $4^{\text {th }}$ Annual Campbell Collaboration Colloquium, Washington DC, 2004.

6. Shaxson L. Is your evidence robust enough? Questions for policy makers and practitioners. Evidence and Policy: A Journal of Research, Debate and Practice, 2005; 1 (1); 101-111.

7. Last JM, ed. A Dictionary of Epidemiology. 3rd ed. New York, NY: Oxford University Press, 1995.

8. Marston G, Watts R. Tampering with the Evidence: A Critical Appraisal of EvidenceBased Policymaking. The Drawing Board: An Australian Review of Public Affairs, 2003; 3 (3): 143-163.

9. Rosales R, Stallones L. Coverage of motor vehicle crashes with injuries in the U.S. newspapers, 1999- 2002. Journal of Safety Research, 2008; 39(5): 477-482.

10. Yankson IK, Browne ENL, Tagbor H, Donkor P, Quansah R, Ernest Asare G, Mock C, Ebel B. Reporting on road traffic injury: content analysis of injuries and prevention opportunities in Ghanaian newspapers. Injury Prevention, 2010; 16; 194-197.

11. Cook FL, Tyler TR, Goetz EG, Gordon M, Proless D, Leff D, Molotch H. Media and agenda setting: effects on the public, interest group leaders, policy makers and policy. Public Opinion Quarterly, 1983; 47 (1): 16-35.

12. Wallack L, Dorfman L. Media advocacy: a strategy for advancing policy and promoting health. Health Educ Quarterly, 1996; 23:293-317.

13. Cooper B, Lee W, Goldacre B, Sanders T. The quality of the evidence for dietary advice given in UK national newspapers. Public Understanding of Science, 2012; 21(6): 664673.

14. Abeysinghe S, Parkhurst J. 'Good' evidence for improved policy making: from hierarchies to appropriateness. Working Paper \# 2. London School of Hygiene and Tropical Medicine GRIP-Health Programme, 2013. 


\begin{tabular}{|l|l|}
\hline Professional category & Percentage of respondents \\
\hline Corporate services & 21.5 \\
\hline Community Development & 20 \\
\hline Technical Services & 17.2 \\
\hline Planning & 15.7 \\
\hline Public Health & 10.5 \\
\hline Parks and Gardens & 3.8 \\
\hline Library Services & 3.8 \\
\hline Customer Service & 2.8 \\
\hline Engineering & 2.4 \\
\hline Other & 2.3 \\
\hline
\end{tabular}

Table One - Professional category of respondents

\begin{tabular}{|l|l|}
\hline Primary source of evidence & Percentage of respondents \\
\hline Local evidence & 17.6 \\
\hline Statewide evidence & 17.7 \\
\hline Complaints/enquiries received & 5.1 \\
\hline See consequences of these risks in the local community & 24.5 \\
\hline Covered in the media & 16.2 \\
\hline Organisational priority & 6.0 \\
\hline Directorate priority & 6.0 \\
\hline Hunch & 5.2 \\
\hline Other & 1.7 \\
\hline
\end{tabular}

Table Two - Primary sources of evidence for public health policy 